\title{
Sistem Pendukung Keputusan Pemilihan Pegawai Honorer Kelurahan Babura dengan Metode MFEP
}

\author{
Supiyandi", Andysah P. U. Siahaan, Alfiandi \\ Fakultas Sains dan Teknologi, Program Studi Sistem Komputer, Universitas Pembangunan Panca Budi, Medan, Indonesia \\ Email: ${ }^{1}$ supiyandi@dosen.pancabudi.ac.id, ${ }^{2}$ andiesiahaan@gmail.com \\ Email Penulis Korespondensi: supiyandi@dosen.pancabudi.ac.id
}

\begin{abstract}
Abstrak-Pegawai adalah seorang yang bekerja pada perusahaan dengan waktu yang telah ditentukan dan juga dengan gaji yang telah ditentukan juga. Pegawai honor memiliki fasilitas yang lebih sedikit dari pegawai tetapi. Sebuah perusahaan tidak bertanggung jawab untuk menyediakan berbagai tunjangan pemberi kerja tradisional, termasuk pajak, jaminan sosial dan kompensasi pekerja. Begitu juga pada kelurahan, setiap Kelurahan memiliki beberapa orang pegawai yang tidak tetap untuk membantu kerja dari Kelurahan tersebut, termasuk di Kelurahan Babura. Kelurahan ini juga memiliki beberapa orang sebagai pegawai honor. Dalam periode tertentu, pegawai honor akan berganti dan akan digantikan oleh orang-orang yang baru. Tetapi untuk memilih pegawai honor tidak juga dapat dilakukan dengan mudah. Ada beberapa persyaratan yang harus dipenuhi agar calon pegawai honor tersebut diterima dengan baik. Beberapa kriteria akan diperhitungkan untuk melakukan proses seleksi calon pegawai honor ini. Sistem pendukung keputusan adalah metode yang baik dalam menentukan pegawai yang layak atau tidak. Metode Multi Factor Evaluation Process (MFEP) dapat membantu pihak Kelurahan dalam menentukan siapa yang akan terpilih untuk menjadi pegawai honor di kantor tersebut. Dengan menerapkan metode ini, KelurahanBabura akan sangat terbantu untuk menilai calon pegawai honor yang akan dipekerjakan di Kelurahan tersebut.
\end{abstract}

Kata Kunci: Sistem Pendukung Keputusan, Pegawai, Honorer, Kelurahan, MFEP

\begin{abstract}
The employee is a person who works at the company with a predetermined time and also with a fixed salary as well. Honorary employees have fewer facilities than employees but. A company is not responsible for providing various traditional employer benefits, including taxes, social security and workers' compensation. Like a wise in the village office of Babura, each village office has a number of temporary employees to help work from the village office, including in Babura village office. This village also has several people as honorarium employees. In a certain period, employee salaries will change and will be replaced by new people. But to choose employee salaries cannot also be done easily. There are several requirements that must be met so that the prospective employee is well received. Several criteria will be taken into account in the selection process for prospective employee employees. Decision support systems are a good method of determining which employees are appropriate or not. The Multifactor Evaluation Process (MFEP) method can assist the Babura village office in determining who will be selected to be an honorarium employee at the office. By applying this method, the Babura village office will be greatly helped in assessing prospective employee salaries to be employed in the village office.
\end{abstract}

Keywords: Decision Support System, Employee, Honorary, Village Office, MFEP

\section{PENDAhUluan}

Karyawan merupakan faktor pendukung dalam suatu perusahaan, karena dengan adanya karyawan yang memiliki standar kualifikasi perusahaan maka produktivitas perusahaan harus dijaga dan ditingkatkan. Untuk mendapatkan informasi dengan cepat dan akurat pencapaian karyawan yang sesuai memenuhi kriteria yang diharapkan, diperlukan suatu sistem pendukung keputusan pemilihan karyawan yang berprestasi. Untuk mengetahuinya, dengan metode pengambilan keputusan multi-kriteria dengan menyelesaikan situasi yang rumit dan tidak terstruktur menjadi beberapa bagian dan mengaturnya dalam hierarki[1]. Sistem Pendukung Keputusan menurut berbagai ahli diantaranya Man dan Watson, bahwa Sistem Pendukung Keputusan (SPK) adalah suatu sistem interaktif yang membantu pengambil keputusan melalui penggunaan data dan model-model keputusan untuk memecahkan masalah-masalah yang sifatnya semi terstruktur dan tidak terstruktur[2], [3].

Dalam penelitian sebelumnya[4]. Sistem Pendukung Keputusan merupakan sistem informasi yang interaktif untuk membantu pengambilan keputusan dalam situasi semitersktruktur dan situasi yang tidak terstruktur seperti ini. Dengan adanya sistem pendukung keputusan dapat membantu kepala dinas selaku pengambil keputusan untuk memilih tanaman pangan yang layak ditanam oleh petani-petani di Kabupaten Musi Rawas. Sistem pendukung keputusan yang saat ini berkembang ada bermacam-macam, salah satunya metode Multi Factor Evaluation Process. Pengambilan keputusan menggunakan metode Multi Factor Evaluation Process dilakukan secara subyektif dan intuitif dengan menimbang beberapa faktor yang berpengaruh terhadap alternative[5].

Penelitian di [6]. Beragam teknik dan aplikasi telah dikembangkan untuk menyelesaikan ketidaktepatan penilaian kinerja perusahaan, yaitu salah satunya berupa system pendukung keputusan (SPK). Aplikasi-aplikasi SPK untuk membantu memberikan penilaian telah dikembangkan, di antaranya untuk menentukan karyawan, mahasiswa atau guru terbaik[7]-[9], penerimaan karyawan, dan penilaian kinerja pegawai dan promosi pegawai[10][11], TOPSIS di [12], WASPAS di [9]. Dalam sistem pendukung keputusan membutuhkan bobot di penelitian [13]. Bobot di peruntukkan pada tiap tiap kriteria yang berbeda beda. Dalam penentuan bobot pada suatu kriteria akan lebih baik menggunakan AHP[14]. Sistem pendukung keputusan juga dapat diterapkan pada permasalahan dibidang industri robot, bahkan mampu membantu para industri kecil sampai yang besar sekalipun 
JURNAL MEDIA INFORMATIKA BUDIDARMA

Volume 4, Nomor 3, Juli 2020, Page 567-573

ISSN 2614-5278 (media cetak), ISSN 2548-8368 (media online)

Available Online at https://ejurnal.stmik-budidarma.ac.id/index.php/mib

DOI $10.30865 /$ mib.v4i3.2107

dalam efektifitas strategi pemasaran suatu wilayah[15] dan keberlanjutannya pada bisnis yang lebih luas seperti pemilihan area bandara[16]. DSS bermula dari SIM karena menekankan pada fungsi mendukung pembuat keputusan diseluruh tahap-tahapnya, meskipun keputusan aktual tetap wewenang eksklusif pembuat keputusan[17].

Dalam penilaian penerimaan calon Tenaga Honorer, sehingga hasil penilaian dan pertimbangan pengambilan keputusan cenderung biasa dan subjektif. Hal ini membuat pengambilan keputusan melakukan penilaian dan pertimbangan, sehingga cenderung terjadi kesalahpahaman dalam pengambilan keputusan penerimaan Tenaga Honorer baru yang sesuai dengan kriteria secara maksimal. Alasan tersebut menjadikan pembuatan suatu model dalam pengambilan keputusan merupakan suatu hal penting, sehingga keputusan yang diambil merupakan keputusan yang akurat, cermat dan tentu saja menguntungkan bagi yang bersangkutan.Model pengambilan keputusan yang dapat dipakai salah satunya adalah Multi Factor Evaluation Process (MFEP). Dalam metode MFEP ini pengambilan keputusan dilakukan dengan memberikan pertimbangan subyektif dan instutif terhadap faktor yang dianggap penting. Pertimbanganpertimbangan tersebut berupa pemberian bobot (weighting system) atas multifaktor yang terlibat dan dianggap penting[18].

\section{METODOLOGI PENELITIAN}

\subsection{Kerangka Penelitian}

Kerangka penelitian terdiri dari beberapa tahapan yang akan dilaksanakan dalam mencapai tujuan penelitian. Ada beberapa fase dimana penelitina yang berhubungan dengan pemilihan pegawai honore pada Kelurahan Babura. Gambar 1 berikut adalah fase-fase yang dikerjakan untuk mendukung implementasi aplikasi dengan metode Multi Factor Evaluation Process (MFEP) yang akan ditunjukkan di bawah ini:

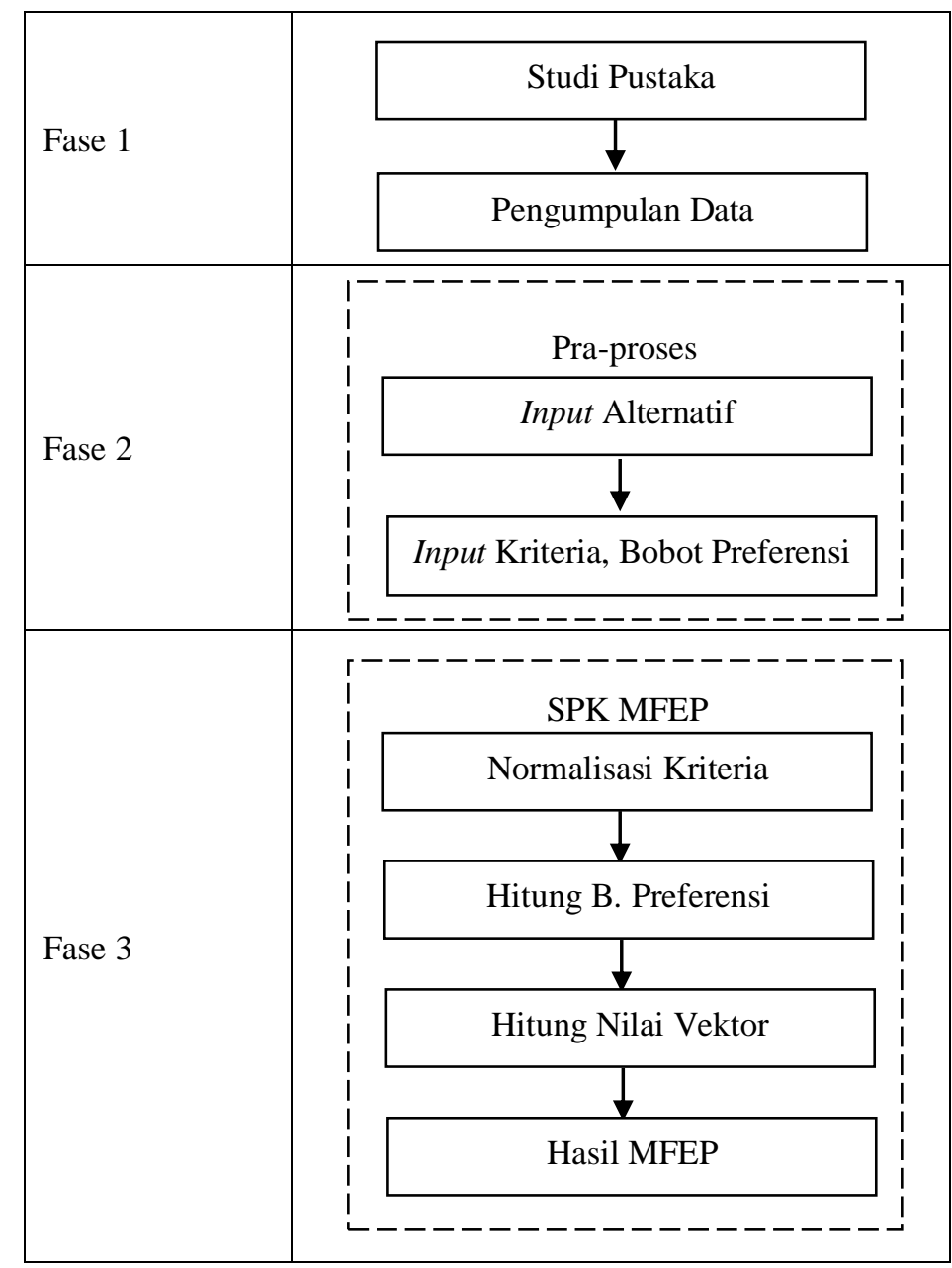

\subsection{Tahapan Penelitian}

Gambar 1. Fase-fase pada Kerangka Penelitian

Ada beberapa tahapan yang perlu dilakukan dalam mencapai hasil yang maksimal. Penelitian ini dilakukan berdasarkan pengambilan data calon pegawai honor di Kelurahan Babura. Sistem pendukung keputusan MFEP 
akan melakukan pengolahan data hingga mendapatkan hasil rekomendasi pegawai honor yang layak dipekerjakan di Kelurahan Babura tersebut. Hasil rekomendasi adalah perbandingan beberapa calon pegawai honor berdasarkan hasil perbandingan kriteria. Tahapan berikut ini adalah langkah-langkah yang harus dicapai dalam melakukan penelitian dalam menentukan calon pegawai honor terbaik ditunjukkan pada gambar 2 berikut:

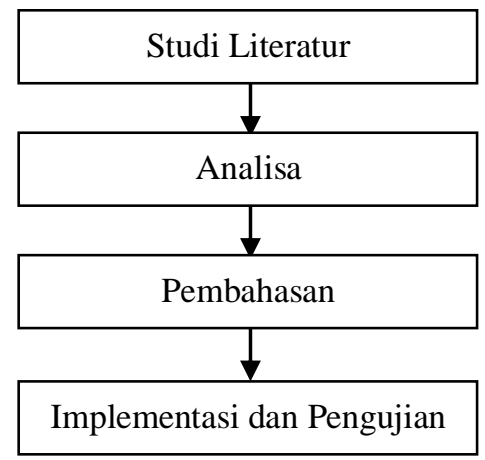

Gambar 2. Tahapan Penelitian

Berikut merupakan penjelasan dari gambar tahapan penelitian yang ada di atas:

1. Studi Literatur

Studi literatur merupakan pencarian sumber daya yang dilakukan berdasarkan sumber-sumber yang berhubungan pegawai honor dan metode MFEP. Pembelajaran dapat diperoleh dari buku-buku, jurnal atau internet dalam mencari bahan-bahan yang berkaitan dengan metode tersebut.

2. Analisa

Analisa dilakukan untuk menentukan teknik penyelesaian suatu rumusan masalah. Perancangan dilakukan berdasarkan oleh studi kasus yang terjadi di Kelurahan Babura. Hal ini mendukung permasalahan tersebut dapat diselesaikan dengan metode MFEP.

3. Pembahasan

Pembahasan dilakukan dengan melakukan perhitungan sistem pendukung keputusan dengan metode MFEP dalam menentukan calon pegawai honor di Kelurahan Babura. Hasil diperoleh berdasarkan kriteria dan bobot preferensi yang sudah ditentukan pada perancangan kriteria.

4. Implementasi dan pengujian

Implementasi dan pengujian merupakan penerapan hasil program aplikasi dan hasik pehitungan sistem pendukung keputusan metode MFEP dalam menentukan calon pegawai honor di Kelurahan Babura.

\subsection{Sistem Pendukung Keputusan}

Menurut Suryadi dan Ramdhani dalam penelitian[3]. Aplikasi DSS menggunakan data, memberikan antarmuka pengguna yang mudah dan dapat menggabungkan pemikiran pengambil keputusan. DSS lebih ditujukan untuk mendukung manajemen dalam melakukan pekerjaan yang bersifat analitis dalam situasi yang kurang terstruktur dan dengan kriteria yang kurang jelas. DSS tidak dimaksudkan untuk mengotomatisasikan pengambilan keputusan tetapi memberikan perangkat interaktif yang memungkinkan pengambil keputusan untuk melakukan berbagai analisis menggunakan model-model yang tersedia.

\subsection{Metode Multi Factor Evaluation Process (MFEP)}

Pendapat di [4]. Pengambilan keputusan menggunakan metode Multi Factor Evaluation Process dilakukan secara subyektif dengan menimbang beberapa faktor yang berpengaruh terhadap alternatif. Langkah-langkah proses perhitungan menggunakan metode MFEP, yaitu :

1. Menentukan faktor dan bobot faktor dimana total pembobotan harus sama dengan 1 ( $\sum$ pembobotan $=$ atau disebut factor weight.

2. Mengisikan nilai tiap faktor yang di perlukan dalam proses pengambilan keputusan, nilai yang dimasukan merupakan nilai objektif yaitu factor evaluation yang nilainya $0-1$

3. Proses perhitungan weight evaluation merupakan perhitungan antara factor weight dan factor evaluation dengan penjumlahan, dari hasil weight evaluation dapat menentukan hasil evaluasi.

Dari langkah proses perhitungan menggunakan metode MFEP di atas dapat direalisasikan sebagai berikut:

1. Perhitungan nilai bobot evaluasi factor ditunjukkan dalam persamaan (1).

$$
E F=\frac{\sum x}{\sum x \max }
$$

Keterangan:

$$
E F
$$

: Evaluasi Faktor 
JURNAL MEDIA INFORMATIKA BUDIDARMA

Volume 4, Nomor 3, Juli 2020, Page 567-573

ISSN 2614-5278 (media cetak), ISSN 2548-8368 (media online)

Available Online at https://ejurnal.stmik-budidarma.ac.id/index.php/mib

DOI 10.30865/mib.v4i3.2107

$\begin{array}{ll}X & \text { : Nilai Subkriteria } \\ X \max & \text { : Nila } \mathrm{x} \max \end{array}$

2. Perhitungan nilai bobot evaluasi ditunjukkan dalam persamaan (2).

$W E=F W \times E$

Keterangan:

$W E \quad$ : Nilai bobot evaluasi

$F W \quad$ : Nilai bobot factor

$E \quad$ : Nilai evaluasi faktor

3. Perhitunga nilai total evaluasi ditunjuk dalam persamaan (3).

$\sum_{i=1}^{n} W E_{i}=W E_{1}+W E_{2}+W E_{n}$

Keterangan:

$\sum_{i=1}^{n} W E_{i} \quad:$ Total nilai bobot evaluasi

$W E_{i} \quad$ : Nilai bobot evaluasi ke $-i$

\section{HASIL DAN PEMBAHASAN}

\subsection{Kriteria dan Alternatif}

Kriteria adalah parameter yang menjadi penentu dalam menentukan calon pegawai honor di Kelurahan Babura. Dalam menentukan kriteria, ada beberapa faktor yang harus diperhatikan agar hasil yang keluarkan menjadi akurat. Kriteria yang digunakan ada sebanyak lima kriteria. Berikut ini adalah kriteria lengkap yang dilakukan beserta nilai bobotnya.

Tabel 1. Kriteria Pendidikan

\begin{tabular}{ccc}
\hline Kriteria Pendidikan & Bobot & Keterangan \\
\hline SMU & 1 & Buruk \\
D1 & 2 & Kurang \\
D3 & 3 & Cukup \\
S1 & 4 & Baik \\
S2 / S3 & 5 & Sangat Baik \\
\hline
\end{tabular}

Tabel 2. Kriteria Umur

\begin{tabular}{ccc}
\hline Kriteria Umur & Bobot & Keterangan \\
\hline$<20$ tahun & 1 & Buruk \\
20 tahun -25 tahun & 3 & Cukup \\
26 tahun -30 tahun & 5 & Sangat Baik \\
31 tahun -40 tahun & 4 & Baik \\
$>40$ tahun & 2 & Kurang \\
\hline
\end{tabular}

Tabel 3. Kriteria Jarak

\begin{tabular}{ccc}
\hline Kriteria Jarak & Bobot & Keterangan \\
\hline $0 \mathrm{~km}-2 \mathrm{~km}$ & 1 & Buruk \\
$2 \mathrm{~km}-4 \mathrm{~km}$ & 2 & Kurang \\
$4 \mathrm{~km}-7 \mathrm{~km}$ & 3 & Cukup \\
$7 \mathrm{~km}-10 \mathrm{~km}$ & 4 & Baik \\
$>10 \mathrm{~km}$ & 5 & Sangat Baik \\
\hline
\end{tabular}

Tabel 4. Kriteria Jenis Tinggi Badan

\begin{tabular}{ccc}
\hline Jenis Tinggi Badan & Bobot & Keterangan \\
\hline$<150 \mathrm{~cm}$ & 1 & Buruk \\
$150-160 \mathrm{~cm}$ & 2 & Kurang \\
$160-170 \mathrm{~cm}$ & 4 & Baik \\
$170-180 \mathrm{~cm}$ & 5 & Sangat Baik \\
$>180 \mathrm{~cm}$ & 3 & Cukup \\
\hline
\end{tabular}


Tabel 5. Kriteria Nilai Test

\begin{tabular}{ccc}
\hline Kriteria Nilai Test & Bobot & Keterangan \\
\hline $0-50$ & 1 & Buruk \\
$50-60$ & 2 & Kurang \\
$60-70$ & 3 & Cukup \\
$70-80$ & 4 & Baik \\
$>80$ & 5 & Sangat Baik \\
\hline
\end{tabular}

Tabel 1 hingga tabel 5 adalah penentuan nilai masing-masing kriteria pada sistem pendukung keputusan pemilihan calon pegawai honor. Penilaian atau bobot diberikan dengan skala 1 hingga 5 dimana nilai 1 adalah untuk penilaian terburuk dan 5 adalah untuk penilaian terbaik.

\subsection{Penerapan Metode MFEP}

Beberapa variabel yang menjadi parameter input harus dipenuhi sebelum melakukan perhitungan. Gambaran perhitungan lengkap tentang menentukan pegawai terbaik sebagai berikut:

Tabel 6. Data Awal

\begin{tabular}{clccccc}
\hline No. & \multirow{2}{*}{ Alternatif } & $\begin{array}{c}\text { Pendidikan } \\
\text { C1 }\end{array}$ & $\begin{array}{c}\text { Umur } \\
\text { C2 }\end{array}$ & $\begin{array}{c}\text { Jarak } \\
\text { C3 }\end{array}$ & $\begin{array}{c}\text { Tinggi Badan } \\
\text { C4 }\end{array}$ & $\begin{array}{c}\text { Nilai Test } \\
\text { C5 }\end{array}$ \\
\hline 1. & Suci & Baik & Kurang & Kurang & Sangat Baik & Kurang \\
2. & Nurul & Kurang & Buruk & Kurang & Baik & Buruk \\
3. & Adil & Baik & Cukup & Cukup & Sangat Baik & Cukup \\
4. & Jhon & Kurang & Buruk & Kurang & Sangat Baik & Buruk \\
5. & Dani & Baik & Cukup & Sangat Baik & Sangat Baik & Cukup \\
6. & Bayu & Sangat Baik & Cukup & Baik & Sangat Baik & Baik \\
7. & Adam & Baik & Kurang & Cukup & Sangat Baik & Kurang \\
8. & Desy & Baik & Cukup & Cukup & Baik & Kurang \\
9. & Rizki & Baik & Cukup & Cukup & Sangat Baik & Cukup \\
10. & Sita & Baik & Cukup & Baik & Sangat Baik & Buruk \\
\hline
\end{tabular}

Berikut ini akan dijelaskan bagaimana metode MFEP dalam menentukan perangkingan berdasarkan kriteria yang sudah ditentukan pada penerimaan calon pegawai pada Kelurahan Babura.

Tabel 7. Data Setelah Pembobotan

\begin{tabular}{clccccc}
\hline No. & Alternatif & $\begin{array}{c}\text { Pendidikan } \\
\text { C1 }\end{array}$ & $\begin{array}{c}\text { Umur } \\
\text { C2 }\end{array}$ & $\begin{array}{c}\text { Jarak } \\
\text { C3 }\end{array}$ & $\begin{array}{c}\text { Tinggi Badan } \\
\text { C4 }\end{array}$ & $\begin{array}{c}\text { Nilai Test } \\
\text { C5 }\end{array}$ \\
\hline 1. & Suci & 4 & 2 & 2 & 5 & 2 \\
2. & Nurul & 2 & 1 & 2 & 4 & 1 \\
3. & Adil & 4 & 3 & 3 & 5 & 3 \\
4. & Jhon & 2 & 1 & 2 & 5 & 1 \\
5. & Dani & 4 & 3 & 5 & 5 & 3 \\
6. & Bayu & 5 & 3 & 4 & 5 & 4 \\
7. & Adam & 4 & 2 & 3 & 5 & 2 \\
8. & Desy & 4 & 3 & 3 & 4 & 2 \\
9. & Rizki & 4 & 3 & 3 & 5 & 3 \\
10. & Sita & 4 & 3 & 4 & 5 & 2 \\
\hline
\end{tabular}

Tabel 8. Bobot Preferensi

\begin{tabular}{cccc}
\hline Kriteria & Bobot & N. Bobot & Percent \\
\hline C1 & 5 & 0,2941 & $29 \%$ \\
C2 & 3 & 0,1765 & $18 \%$ \\
C3 & 3 & 0,1765 & $18 \%$ \\
C4 & 4 & 0,2353 & $24 \%$ \\
C5 & 2 & 0,1176 & $12 \%$ \\
Jumlah & $\mathbf{1 7}$ & $\mathbf{1}$ & $\mathbf{1 0 0 \%}$ \\
\hline
\end{tabular}

Analisa perhitungan MFEP sebagai berikut :

$$
\begin{array}{ll}
\text { Suci } & =(4 * 0.2941)+(2 * 0.1765)+(2 * 0.1765)+(5 * 0.2353)+(2 * 0.1176)=3.2941 \\
\text { Nurul } & =(2 * 0.2941)+(1 * 0.1765)+(2 * 0.1765)+(4 * 0.2353)+(1 * 0.1176)=2.1765 \\
\text { Adil } & =(4 * 0.2941)+(3 * 0.1765)+(3 * 0.1765)+(5 * 0.2353)+(3 * 0.1176)=3.7647 \\
\text { Jhon } & =(2 * 0.2941)+(1 * 0.1765)+(2 * 0.1765)+(5 * 0.2353)+(1 * 0.1176)=2.4118 \\
\text { Dani } & =(4 * 0.2941)+(3 * 0.1765)+(5 * 0.1765)+(5 * 0.2353)+(3 * 0.1176)=4.1177
\end{array}
$$




$$
\begin{aligned}
& \text { Bayu }=(5 * 0.2941)+(3 * 0.1765)+(4 * 0.1765)+\left(5^{*} 0.2353\right)+(4 * 0.1176)=4.3529 \\
& \text { Adam }=(4 * 0.2941)+(2 * 0.1765)+(3 * 0.1765)+(5 * 0.2353)+(2 * 0.1176)=3.4706 \\
& \text { Desy }=(4 * 0.2941)+(3 * 0.1765)+(3 * 0.1765)+(4 * 0.2353)+(2 * 0.1176)=3.4118 \\
& \text { Rizki }=(4 * 0.2941)+(3 * 0.1765)+(3 * 0.1765)+(5 * 0.2353)+(3 * 0.1176)=3.7647 \\
& \text { Sita }=(4 * 0.2941)+(3 * 0.1765)+(4 * 0.1765)+(5 * 0.2353)+(2 * 0.1176)=3.8236
\end{aligned}
$$

Tabel 9. Hasil MFEP

\begin{tabular}{cll}
\hline No. & Alternatif & MFEP \\
\hline 1. & Suci & 3.2941 \\
2. & Nurul & 2.1765 \\
3. & Adil & 3.7646 \\
4. & Jhon & 2.4118 \\
5. & Dani & 4.1177 \\
6. & Bayu & 4.3529 \\
7. & Adam & 3.4706 \\
8. & Desy & 3.4118 \\
9. & Rizki & 3.7647 \\
10. & Sita & 3.8236 \\
\hline
\end{tabular}

Berdasarkan Tabel 9 diatas, dapat dilihat bahwa calon untuk menjadi pegawai honorer adalah alternative Bayu dengan Nilai 4.3529.

\section{KESIMPULAN}

Penelitian ini belum tentu memberikan kontribusi yang besar dan masih sangat membutuhkan pengembangan lebih lanjut agar menjadi lebih baik. Adapun beberapa kesimpulan yang dapat dikemukakan pada penelitian ini antara lain:

1. Metode MFEP dapat digunakan dalam menentukan calon pegawai honor pada Kelurahan Babura.

2. Kriteria yang digunakan sebaiknya ditambahkan agar memberikan tingkat akurasi yang baik.

3. Bobot preferensi dapat dikembangkan sehingga memberikan akurasi dan hasil keputusan yang lebih baik.

4. Bobot preferensi dapat memberikan variasi hasil terhadap alternatif yang diolah.

\section{UCAPAN TERIMAKASIH}

Terima kasih disampaikan kepada pihak-pihak yang telah mendukung terlaksananya penelitian ini.

\section{REFERENCES}

[1] K. Safitri, F. T. Waruwu, and M. Mesran, "SISTEM PENDUKUNG KEPUTUSAN PEMILIHAN KARYAWAN BERPRESTASI DENGAN MENGGUNAKAN METODE ANALYTICAL HIEARARCHY PROCESS (Studi Kasus : PT.Capella Dinamik Nusantara Takengon)," MEDIA Inform. BUDIDARMA, vol. 1, no. 1, pp. 12-16, 2017.

[2] N. W. Al-Hafiz, Mesran, and Suginam, "Sistem Pendukung Keputusan Penentukan Kredit Pemilikan Rumah Menerapkan Multi-Objective Optimization on the Basis of Ratio Analysis ( Moora )," KOMIK (Konferensi Nas. Teknol. Inf. dan Komputer), vol. I, no. 1, pp. 306-309, 2017.

[3] S. Supiyandi and M. Zen, "Sistem Pendukung Keputusan Proses Kenaikan Jabatan dan Perencanaan Karir Pada PT. ABC Dengan Metode Profile Matching," Algoritm. J. ILMU Komput. DAN Inform., vol. 3, no. 1, p. 55, Apr. 2019.

[4] Y. Primadasa and V. Amalia, "Penerapan Metode Multi Factor Evaluation Process untuk Pemilihan Tanaman Pangan di Kabupaten Musi Rawas," Sisfo, vol. 07, no. 01, pp. 47-58, 2017.

[5] D. M. Khairina, B. Santoso, and S. Maharani, "Penerapan Metode Technique For Others Preference By Similary To Ideal Solution (TOPSIS) Untuk Rekomendasi Pemilihan TV Layar Datar," J. Nas. Teknol. dan Sist. Inf., vol. 2, no. 1, pp. 23-34, 2016.

[6] T. Imandasari and A. P. Windarto, "Sistem Pendukung Keputusan dalam Merekomendasikan Unit Terbaik di PDAM Tirta Lihou Menggunakan Metode Promethee," J. Teknol. dan Sist. Komput., vol. 5, no. 4, p. 159, Oct. 2017.

[7] I. Herman Firdaus, G. Abdillah, F. Renaldi, and U. Jenderal Achmad Yani Jl, "Sistem Pendukung Keputusan Penentuan Karyawan Terbaik Menggunakan Metode Ahp Dan Topsis," Semin. Nas. Teknol. Inf. dan Komun., vol. 2016, no. Sentika, pp. 2089-9815, 2016.

[8] F. S. Priyanto, B. Harijanto, and Y. Watequlis, "SISTEM PENDUKUNG KEPUTUSAN PEMILIHAN GURU BERPRESTASI MENGGUNAKAN METODE PROMETHEE (Studi Kasus: Dinas Pendidikan Kota Malang), $J$. Inform. Polinema, vol. 3, no. 4, p. 23, 2017.

[9] S. Barus, V. M. Sitorus, D. Napitupulu, M. Mesran, and S. Supiyandi, "Sistem Pendukung Keputusan Pengangkatan Guru Tetap Menerapkan Metode Weight Aggregated Sum Product Assesment (WASPAS)," J. MEDIA Inform. BUDIDARMA, vol. 2, no. 2, 2018.

[10] R. Hidayat, "Menentukan Promosi Jabatan Karyawan dengan Menggunakan Metode Profile Matching dan Metode Promethee," IJSE - Indones. J. Softw. Eng., vol. 2, no. 1, pp. 57-65, 2016. 
[11] M. Purwokerto et al., "Sistem Pendukung Keputusan Penilaian Kinerja Karyawan Menggunakan Metode SAW ( Simple Additive Weighting ) di Universitas Muhammadiyah Purwokerto ( Decision Support System of Human Resources Performance Assessment Using SAW ( Simple Additive Weighting ) M,” JUITA J. Inform., vol. III, no. November, pp. 193-200, 2015.

[12] R. Rahim et al., "TOPSIS Method Application for Decision Support System in Internal Control for Selecting Best Employees," J. Phys. Conf. Ser., vol. 1028, no. 1, 2018.

[13] A. S. R. A. Binjori, H. R. B. Hutapea, and M. Syahrizal, "Sistem Pendukung Keputusan Pemilihan Operator Seluler Menggunakan Metode Multi-Objective Optimization on the Basis of Ratio Analysis (Moora)," KOMIK (Konferensi Nas. Teknol. Inf. dan Komputer), vol. 2, no. 1, pp. 61-65, 2018.

[14] H. Nurdiyanto and H. Meilia, "Sistem Pendukung Keputusan Penentuan Prioritas Pengembangan Industri Kecil Dan Menengah Di Lampung Tengah Menggunakan Analitical Hierarchy Process (Ahp)," Semnasteknomedia Online, vol. 4, no. 1, pp. 3-3-37, 2016.

[15] S. D. U. Sutiksno, P. Rufaidah, H. Ali, and W. Souisa, "A Literature Review of Strategic Marketing and The Resource Based View of The Firm," Int. J. Econ. Res, vol. 14, no. 8, pp. 59-73, 2017.

[16] M. I. Setiawan et al., "Business Centre Development Model of Airport Area in Supporting Airport Sustainability in Indonesia," in Journal of Physics: Conference Series, 2018, vol. 954, no. 1, p. 12024.

[17] H. Syahputra, M. Syahrizal, S. Suginam, S. D. Nasution, and B. Purba, "SPK Pemilihan Konten Youtube Layak Tonton Untuk Anak-Anak Menerapkan Metode Additive Ratio Assessment (ARAS)," Semin. Nas. Teknol. Komput. Sains, vol. 1, no. 1, pp. 678-685, 2019.

[18] R. Turaina and C. Gustia E, "Sistem Penunjang Keputusan Penerimaan Calon Tenaga Honorer Di Sma N 1 Junjung Sirih Kab. Solok Menggunakan Metode Multifaktor Evaluasi Proses (Mfep),” J. Momentum, vol. 18, no. 2, pp. 60-66, 2016. 